\title{
The effect of asking current consumption questions before or after product evaluation
}

Received: (in revised form): 1st September, 2003

\section{Roy F. Cabaniss}

is an associate professor of marketing at the University of Arkansas Monticello in Monticello, Arkansas. With research interests in satisfaction, business-to-business, logistics and computer utilisation, he is heavily involved with Open Source software and Linux in general. He has designed computer games and does a lot of work with databases both for his college and businesses.

Roy F. Cabaniss University of Arkansas Monticello, Box 3616, Monticello, Arkansas 71656, USA.

Tel: +1 870460 1440; Fax: +1 870460 1784; e-mail: rcaban@cabanisspc. uamont.edu website: http:// cabanisspc.uamont.edu

\section{INTRODUCTION}

One of the primary tasks of marketing research is the evaluation of a product and gathering customers' opinions about that product. Product evaluations can take many forms and are encountered constantly. People go to the supermarket and are asked to try a sample of a product. Comparative advertising often occurs with food goods. The salesperson for an insurance company makes comparisons between insurance plans. A customer test drives a new car after arriving in the old banger. Virtually every purchase decision is accompanied by an evaluation of the product or service.

When product-oriented market research is performed via a survey there are essentially two places where questions regarding the subject's current consumption patterns can be recorded. This can be either before the subject has evaluated the 'new' product or after the 'new' product evaluation. Remembering that the new product evaluation is the item of interest, a question should arise as to the impact of the referent question's location.

The objectives of this paper are to consider:

- whether the location of the current consumption questions in the survey instruments alters the evaluation scoring of the product of interest. If the referent questions are before the evaluation of interest it is logical to encounter some reference effects due to the cognitive effort necessary to respond to current consumption pattern questions; 
- if the current consumption question location does affect the evaluation scoring, is the impact positive or negative? Does the systemic bias engendered by the current consumption question location lead to a higher evaluation or a lower one;

- the mechanism by which the current consumption question location acts. Does it act via an alteration in the information processing or is it due to reference effects?

\section{LITERATURE REVIEW}

When discussing product evaluation, there are a lot of different ways to approach it - from the deliberate evaluation of expectations, ${ }^{1}$ to the impact of extrinsic cues ${ }^{2-6}$ and the interactions of affect and cognitive responses. ${ }^{7}$

One area which has not received a great deal of attention is the impact of prior product evaluations/consumption experiences. Conventional wisdom would have it that the consumer's prior consumption experiences would alter their evaluation of a new product, but this is one of those areas in which conventional wisdom has not been tested. The basic concept here is that consumers do not enter into a consumption experience with a clean slate. However those evaluations of a consumption experience are to be measured, be it measuring satisfaction, product quality or product characteristics the prior consumptive experiences need to be taken into account. An experiment to determine the magnitude and sign (positive or negative) of the customer's prior consumption would help researchers take those prior evaluations into account when evaluating the potential for a new product.

The type of information processing a person does is not the same for all individuals. In fact the same individual can undergo at least four different types of information processing. Biehal and Chakravarti $^{8}$ classified these forms of processing as:

- attribute processing

- paired comparisons

- brand processing

- holistic comparisons.

Each of these types of information processing has antecedent conditions attached and there is no real telling which of those types of information processing the customer is doing when they evaluate the product. Another question is how much influence the type of processing has on the measured outcome.

\section{METHOD}

\section{Scales}

The first necessity is to find a product in which the consumers could not identify the brand. This was judged necessary so that preconceptions about the product would not enter into the experiment. Allison and $\mathrm{Uhl}^{9,10}$ found that beer was such a product. In a blind test it was found that consumers could not differentiate between beer brands including their 'favourite' beer, provided that the test was a 'blind' test.

This finding is important for two reasons. The first is that product quality would, theoretically, have no impact upon the results enabling the researcher to minimise the financial outlay. The second is that an attribute-based perceptual scale was used in their study. This scale used the characteristics of the beer to achieve an overall evaluation score. It also had a position on it that corresponded to 'just right'. This scale 
was destined to be used as the dependent variable in the experiment.

The Allison and Uhl scale as it was originally used consisted of nine specific characteristics:

- aroma
- bitterness
- body
- carbonation
- foam
- lightness
- strength
— sweetness
— aftertaste.

Since this scale was designed to be used by the individuals who were serving their own beer it needed an initial modification. This modification was to not use the foam characteristic. This was deemed necessary because the amount of foam desired is a personal characteristic of each beer drinker. Due to the nature of the experiment, the researcher was pouring the beer, resulting in a constant amount of foam which may or may not have corresponded to the drinker's preferred foam level. In order to replicate the Allison/Uhl scale as much as possible the variable 'foam' was left on the questionnaires but was not used in calculating the eventual scores.

\section{Pretest}

A pretest was conducted to examine the scale for its internal reliability. This was deemed necessary because the original usage of this scale did not perform this task. A sample group of 20 individuals was given the scale and they were asked to evaluate their regular beer upon the characteristics listed. This pretest resulted in two items which had negative item to total correlations and an $\alpha$ of 0.6910 . In accordance with Churchill ${ }^{11}$ the items with the negative item to total correlations were eliminated and another $\alpha$ was calculated to be 0.7866 . Since this $\alpha$ was above the threshold level recommended by Nunneley ${ }^{12}$ no further modification to the scale was deemed necessary.

Another pretest was performed with expert judges performing a blind taste test. Again they could not differentiate between the various brands of beers. The judges were also asked to list the characteristics upon which they based their evaluations of beers. Without prior knowledge of the Allison and Uhl study, the expert panel's list of characteristics mirrored that of the Allison and Uhl study. ${ }^{13}$

\section{Questionnaires}

The questionnaires were constructed with four versions. The sole differences between the different questionnaires lay in the location of the question 'What beer do you normally drink?' and instructions to drink beer A or beer B. With the reality that all beer consumed was of the same brand regardless of letter (A or B) this resulted in two treatments. One in which the participant was asked their normal beer before they evaluated the unknown beer and the other in which the normal consumption question was asked after the new beer was evaluated. The questionnaires were randomly shuffled and placed face down into a bag for administration of the experiment.

\section{Conduct of the experiment}

In an effort to make a more natural environment participants were invited to come to a public park on a spring day to try some beer. Due to financial constraints, provision was only made for 80 participants who were chosen from a list of the inhabitants of a small 
mid-Western town in the USA (of the first 85 people contacted, only five declined to participate). The site was a public park on a warm, clear, spring day. An opaque tent was erected and the beer placed inside so that the participants would not know the brand of the beer they were drinking. The beer was received cold and put on ice immediately upon arrival so that it was kept at the proper serving temperature of $40^{\circ} \mathrm{F}$. Upon arrival at the site the subjects were told to reach into the bag and get a questionnaire. This ensured a random assignment of treatments since the questionnaires were randomised and the subjects' order of arrival at the test site was random also. They then told the researcher which beer the questionnaire called for, A or B. The researcher poured the beer in the tent so that the subjects did not know what beer it was that they were consuming. In every instance the beer that they were given was the same, Anhauser Busch Natural Light. Subjects then proceeded to drink the beer. After they drank the beer they evaluated it upon the modified Allison and Uhl scale and finished the questionnaire.

\section{RESULTS}

The results are organised as follows. First, the manipulation check as to the type of information processing used is reported. Next the hypothesis is examined using ANOVA.

\section{Manipulation check}

The manipulation check consisted of a ten-point Likert-type question placed at the end of the test. This question asked whether the subjects evaluated the beer as a whole. As expected the type of treatment did alter their perceptions of the task which they had just performed $(\mathrm{F}=6.65, \mathrm{df}=79, p<0.05)$ with those who had the reference question at the back of the survey stating they had evaluated the beer in its entirety as opposed to each characteristic individually.

\section{Hypothesis test}

Once the manipulation check was shown to be significant there were three immediate questions. The first of these was the primary question for the hypothesis: did the location of a product referent question in the survey matter? This was answered in the affirmative $(\mathrm{F}=4.64, \mathrm{df}=79, p<0.05)$.

With the location shown to be significant another question presented itself, ie did the treatment have the postulated effect? In other words, did the location difference change the type of processing done by the subjects? There are two pieces of evidence, besides the manipulation check, which would indicate that the treatment did alter the information processing process. The first piece of evidence is that the means for the two treatments are significantly different $(\mathrm{T}=2.02, \mathrm{df}=79, p=0.05)$. When the question about the subject's favourite beer was at the front of the survey, the mean score was 30, whereas when the same question was at the back of the survey the mean score was 37 . This is consistent with the concept of increasing the choice criteria (attribute processing) decreasing the evaluation score. The second piece of evidence lies in the item-to-total correlations of the treatments. When the treatments are separated and item-to-total correlations calculated the pattern of the correlations are different. The holistic evaluations have a higher pattern of correlations than the attribute evaluations and a higher reliability coefficient.

The last question is whether the misdirection on the part of the 
The effect of asking current consumption questions before or after product evaluation

Table 1: Attribute vs Holistic item-to-total correlations

\begin{tabular}{lll}
\hline Variable & $\begin{array}{l}\text { Attribute-corrected } \\
\text { item-to-total correlations }\end{array}$ & $\begin{array}{l}\text { Holistic-corrected } \\
\text { item-to-total correlations }\end{array}$ \\
\hline Aftertaste & 0.1482 & 0.5577 \\
Aroma & 0.5268 & 0.6222 \\
Bitterness & 0.2949 & 0.2388 \\
Body & 0.5592 & 0.1824 \\
Carbonation & 0.0924 & 0.6445 \\
Strength & 0.5014 & 0.6776 \\
Cronbach's $\alpha$ & 0.6034 & 0.6665 \\
\hline
\end{tabular}

Number of cases $=40$ for each treatment

questionnaire, 'Drink a sample of Brand A/Brand B', had an impact on the results. The question as to which of the beers the subjects were to sample was not significant $(\mathrm{F}=0.10, \mathrm{df}=76$, $p=0.7523)$.

\section{CONCLUSIONS}

The primary conclusion derived from this research is that the location of the product questions will alter the evaluation score. If the questions are at the front of the questionnaire the eventual evaluation will be lower than they would be if the questions were at the back. The difference in evaluation scores would appear to be due to different information processing taking place. Given this conclusion, if an unbiased evaluation is desired the locations of the referent product questions must be at different locations throughout a questionnaire. A secondary conclusion which can be derived from this research is that virtually any reference to the normal usage of a product can serve to trigger a change in the information processing mode.

Future research efforts should be a natural offshoot of current efforts. Among the possibilities for future research would be the linking of the involvement construct to the mode of information processing. If this was done then a possible line of research would be in the linkages between involvement, processing mode and the eventual product evaluations.

\section{References}

1 Parasuraman, A., Zeithaml, V. and Berry, L. (1988) 'SERVQUAL: A multiple-item scale for measuring consumer perceptions of service quality', Journal of Retailing, Vol. 64, No. 1, pp. 12-40.

2 Rao, A. R. and Bergan, M. E. (1992) 'Price premium variations as a consequence of buyers' lack of information', Journal of Consumer Research, Vol. 19, September, pp. 412-423.

3 Rao, A. R. and Monroe, K. (1988) 'The moderating effect of prior knowledge on cue utilization in product evaluations', Journal of Consumer Research, Vol. 15, September, pp. 253-264.

4 Rao, A. R. and Monroe, K. (1988) 'The effect of price, brand name and store name on buyer's subjective product assessments: An integrative review', Journal of Marketing Research, Vol. 26, August, pp. 351-357.

5 White, D. and Truly, E. L. (1989) 'Price-quality integration in warranty evaluations', Journal of Business Research', Vol. 19, September, pp. 109-125.

6 Kirmani, A. and Wright, P. (1989) 'Money talks: Perceived advertising expense and expected product quality', Journal of Consumer Research, Vol. 16, December, pp. 344-353.

7 Compeau, L. D., Grewal, D. and Monroe, K. B. (1998) 'Role of prior affect and sensory cues on consumers' affective and cognitive responses and overall perceptions of quality', Journal of Business Research', July, New York.

8 Biehal, G. and Chakravarti, D. (1986) 'Consumers' use of memory and external information in choice: Macro and micro perspectives', Journal of Consumer Research, Vol. 12, No. 4, March, pp. 382-405.

9 Allison, R. I. and Uhl, K. P. (1966) 'Brand identification and perception', Perspectives in Consumer Behavior, Vol. 1, pp. 17-23.

10 Allison, R. I. and Uhl, K. P. (1964) 'Influence of beer brand identification on taste perception', Journal of Marketing Research, Vol. 3, August, pp. 36-39.

11 Churchill, G. A. Jr (1979) 'A paradigm for 
developing better measures of marketing constructs', Journal of Marketing Research, Vol. 16, February, pp. 64-79.

12 Nunneley, J. (1967) 'Psychometric Methods', McGraw-Hill, New York.

13 To be fair to the experts, the beers being compared were all in the category of American lager. Even the experts (and this researcher) can tell the difference between a pint of Guinness and a glass of Budweiser (though an experiment to determine this would not be looked upon with disfavour). (Author's note ... and a good time was had by all.) 